\title{
Exploring the effects of spatial and social segregation in university campuses, IZTECH as a case study
}

Manuscript version

Final version published as:

Berna Yaylali-Yildiz, Claudia Yamu, Ela Cil, 2013,

"Exploring the effects of spatial and social segregation in university campuses, IZTECH as a case study", Urban Design International, online, pp. 1-19, doi:10.1057/udi.2013.19

Berna Yaylali-Yildiz

Izmir Institute of Technology

Department of Architecture

bernayaylali@iyte.edu.tr

Claudia Yamu

Vienna University of Technology

Department of Planning

claudia.yamu@tuwien.ac.at

Ela Cil

Izmir Institute of Technology

Department of Architecture

elacil@iyte.edu.tr 


\begin{abstract}
This study focuses on the spatial configuration of university campuses through the case study of Izmir Institute of Technology (IZTECH), settled outside of the city of Izmir. Isolated university campuses are interesting cases to examine, especially when there is a need to focus on the relationship between the campus life and collective spaces, in which open spaces play a major role. Although these campuses are planned as separate enclaves with the vision that academic life would require isolation, quietness and concentration, we argue that the campus design, especially their open spaces, should generate an interacting community balancing the inwardfocused learning. In addition, we suggest that when a university campus fails to facilitate social gatherings through its spaces, both faculty and students are deprived of the fundamental reason of the university's constitution. This article first presents the spatial analysis (space syntax analysis) examining the potentials of the physical configuration of campus for bringing students together. Second, we present the findings of the questionnaire surveying students' choices for spatial practices. Syntax analysis and survey show that locally integrated lines are not supported with activities. Comparison of the frequency of use in actual practice both on the most integrated lines and on areas with strong visibility show that these spaces are not lived up to their potentials. This article is produced from the corresponding author's ongoing $\mathrm{PhD}$ dissertation at the Izmir Institute of Technology, Faculty of Architecture, under the supervision of Assist. Prof. Dr. Ela Çil
\end{abstract}

Keywords: public space; university campus life; spatial configuration; space syntax analysis; segregation

\title{
Introduction
}

This study is part of an ongoing research examining the relationship between the physical potentials of university campuses in Turkey for supporting and sustaining public life happening in different kinds of spatial practices. Signifi cantly, the aim is to examine the potentials of campus plans when they are intentionally planned to be segregated. The Izmir Institute of Technology (IZTECH) in Turkey is one of the case studies and the focus of the analysis presented in this article. The role of universities for the production of knowledge and as a major contributor to public sphere in general has been largely discussed in the literature (Readings, 1996; Delanty, 1998, 2001a, b, 2008; Calhoun, 2006; Pusser, 2006). There is an overarching concern that universities have lost their emancipatory role to formulate an effective public sphere for a broader public (Readings, 
1996). Proclaiming the 'end of university', recent discussions declare the public mission of universityas inefficient thinking that its role has dimmed in producing and transmitting knowledge. Although these debates open a gateway for discussing the capacity of the university to stimulate and become the major contributor of publicness, they leave out the question on the types of publicness that may occur in the universities, as well as how such publicness occurs in the university campus life and the role that its spatial organization plays on that life. Rather, these discussions mostly focus on the generation of knowledge and its relationship with public sphere. This study addresses this less-explored issue and presents a case study on a campus outside of a city.

\section{A History of University Campus Planning}

According to the literature, the first universities emerged at the end of twelfth century in Europe following Bologna, in Paris and in Oxford. Evolving from the cathedral schools and monasteries, universities had no permanent buildings and they were scattered in existing buildings in the city. However, gathering university facilities in one location became necessary, because of the number of students who enrolled and the fi eld of studies increased. University settlements started to occupy specific locations from eighteenth century onward. With its inward-focused learning community and distinct spatial organization, this settlement was named campus (Neuman, 2003). In literature, we come across four prototypes of university campus designs: European urban university; British college, as a model separated from the European campuses; American campus; and megastructures (Turner, 1987; Davis and Davis, 1990; Hashimshony and Haina, 2006). In the model of the European urban university, free-standing faculty buildings are located in different parts of the city. As Brockliss (2000, p. 154) states, the European university and city had been united throughout history. However, by late nineteenth century, the European urban university assimilated into American university (Bowman, 2011).

From the beginning, physical arrangement of American campus is diverged from a specific European urban campus model: the British college, where students study, live and play in an inclusive setting (Turner, 1987, p. 22). In this spatial model, separate buildings with courtyards gathered around in the open landscape. This was a contrast to most of the university campus designs in Europe that has usually been located dispersed and well integrated into the dense urban fabric. ' Isolated to a great extent from connexion with the community around it' (Turner, 1987, p. 101), campus model was based on the 'idea of knowledge in the midst of the nature for a maximum quietness and concentration' (Christiaanse, 2004, p. 46). ' Removed from the corrupting forces of the city', the campus gathered many other functions in itself for students' comfort and needs 
(Turner, 1987, p. 12). That is why Muthesius (2000, p. 3) identifies this campus model as utopic in terms of its ambition for gathering social and educational facilities in one location and creating a learning community. After the World War II, student population enrollment increased and both American and European universities experienced a new concept in campus design. Referring to megastructure, these new universities were designed as a series of large, single buildings or interconnected buildings integrating different programs within their continuous structure (Davis and Davis, 1990, p. 43). However, the increase in the scale of the buildings caused the destruction of the urban fabric around them (Hashimshony and Haina, 2006, p. 8) and the functional and social segregation of their community.

Beginning in the 1970s in Turkey, as in many countries, most new universities were designed as a combination of the American campus and the megastructure models. Introduction of new types of research, interdisciplinary studies, and more and more people having higher education brought the need of new and bigger buildings that did not fit into cities. University campuses were constructed outside the cities, some of which in time have become to be at the peripheries. Thus, the contrast between the urban university and its integration into urban life and the separated campus that is planned to be self-suffi cient and isolated from an urban context for fostering concentration on studies, such as IZTECH, urges the need for examining how the public life is formed in the university campus remote from the city.

\section{Public Life in the University Campus}

With the activities revolving around creation and transmission of knowledge, university is a setting that gathers youthful and comparatively diversified population (Gumprecht, 2003, p. 54). In its intellectual environment, students, academics and other professionals meet at the intersection of many disciplines. This 'intentional community', consisting of people from differing cultural and economic backgrounds, having different ideas, beliefs and expectations, is made in the university for learning, producing and sharing knowledge (Chapman, 2006, p. xxv). In that respect, perhaps more than towns and cities, university campuses need collective life that serves for the public and private purposes of its inhabitants. Nevertheless, university campus life is different from urban public life in certain ways: In an urban setting, strangers may only enjoy the livelihood of a street or a plaza and do not necessarily interact with each other. However, the users of the campus who gather there with a sense of common purpose and interests interact more in shared spaces of working, studying and living (Halsband, 2005, p. 6). Collective life in the campus is based on the production and transmission of knowledge in addition to social needs of the intellectual environment that would require co-presence and interaction. The need for interaction is perhaps 
more important than in a work environment; it becomes essential in a university campus in terms of sharing and exchanging ideas, interests and goals with others. Otherwise, as Yanni (2006) states, ' academic life turns into disparate, meaningless periods, a walk from class to class, and a retreat into offi ce or labs' . In university campus, socialization is also important to create and foster a learning community in the campus (Chapman, 1999, 2006). Learning community is cultivated in courses, departments, as well as sport teams, social organizations and interest groups. Hence, spaces of learning are not just seminar or lecture rooms. Perhaps what makes university education different from high school is not only the level of the content matter but the whole environment that is a living and learning space, where its members learn how to work together, get into contact with one another and live with different groups. In that respect, university campuses have common roles in shaping a strong sense of community and their social identities. That is why Chapman (2006) defi nes campus as 'cultural landscape' imbued with deep social and educational purposes (p. xxxiv).

Social spaces in academic environment have important roles in the organization of social life. Their rhythms of use are defi ned by curricular activities (Christ, 2005), and during those times these spaces support academicians and students both to share knowledge spontaneously and to participate into co-curricular activities and provide relief from the stresses of busy working time. Bringing together different groups of students, being a platform of different ways of thinking can be the most important contribution of space to the collective life in universities. Social spaces become more effective when they give chances to random encounters and interaction between members of the university. Assuming that university is a place of discovery, and learning is a social activity in this environment (Temple, 2008), random encounters in public spaces increase possibility of talking, discussing and learning. As Chapman (2006) indicates, encounters strengthen ' learning experience through inquiry, direct observation, debate, action and social exchange from the playful to the very serious' (p. xxxii). Freed from working life or family responsibilities, students have the ability to maintain a more fluid allocation of time to experience the different social contexts and environments (Chatterton, 1999, p. 124). That is why Kumar (1997, p. 33) elaborates university campuses as special places for students to explore the larger world with others. In lecture halls, open spaces and public buildings, such as cafeteria or library, students experience being a part of the larger world and the university. On the other hand, when campus, as a place, is not organized with an aspiration to generate and support such public life, especially when it is spatially fragmented and insular, there may be spatio-behavioral implications, such as division, tension, alienation and strife (Whisnant, 1979). 
Although these extensive debates about public life in a campus address the connection between space and publicness, there is less research examining the role of spatial confi guration of university campuses in creating and sustaining a public life. Among these studies, there is a growing literature in the space syntax research. Whereas a group of studies in that area concentrates on the relationship between campus community and community of its surrounding environment (Srouri, 2005; Adhya, 2009), another group concentrates on orientation problems within the campus street systems (Trigueiro and Onofre, 2009; Barros et al ,2009). We are especially reviewing the studies that investigate distribution of people to the use of open space with an analysis of different campus configurations (Greene and Penn, 1997; Kim, 2009; Schwander et al ,2012). Presenting a detailed analysis of central plazas of two campuses, Kim (2009) investigates the reason of different kinds of vitality produced in two plazas. By examining the role of spatial configuration of these plazas in the movement patterns of students, Kim argues that different spatial organizations of the plazas create different types of interaction in campuses. In addition to the plazas' different levels of integration, the number of people using the plazas regularly and the different events developing in and around them are defined as the other reasons of difference in spaces' vitality. Although Kim analyzes the movement patterns of people to measure vitality in the plazas, she does not describe in what kind of practices vitality emerges or what the other elements of vitality can be. In a different aspect, Greene and Penn (1997) show the impact of spatial structure of university campus to the flow of technology. They present that the more integrated the academic units, the more academics know each other and the students, and the higher their frequency of contact with the students and academics of other academic units. Related to the differences in the global and local integration of a campus, they relate powerful local integration in the absence of global integration to reinforce local integration forming largely student-student interaction and solidarity formation. In a parallel way, Schwander and colleagues focus on the spatial confi guration of two different campuses of new universities that are built with an interconnected university model with the intention to foster encounters and informal communication of people from different disciplines. Performing a microanalysis of open spaces in two campuses, they aim to understand the potentials of these spaces for interdisciplinary communication. These studies broadly address how the spatial organization of a university campus infl uences the generation of public life in general. However, the specific attributes of public practices in campuses and the way in which open spaces in the campus outside the city generate different forms of publicness are not yet fully analyzed. Although these studies investigate the relationship between space and changing movement patterns by quantitative methods, they do not question the spatial choices of students for stationary practices in the campus. 
A rethinking on what kind of public practices are experienced in collective spaces that have different physical and spatial characteristics may help us to understand the spatial role of campus and its relationship with different dimensions of a vivid public life. That confi rms Hillier's argument on the balance between use of public spaces and the static occupancy, which is related to the 'strategic value' of space (Hillier, 1996, p. 165; Arruda Campos, 1997). In this respect, this study aims to further the aforementioned research with juxtaposing different methods of analysis and focusing on the different practices constituting public life.

\section{IZTECH Campus}

IZTECH is located within the boundaries of the city of Izmir (Turkey). With a population of about 4 million people, İzmir is located in Turkey's west coast. In Izmir, there are two more public universities other than IZTECH, and five private universities. Established in 1992, IZTECH is settled in a campus $45 \mathrm{~km}$ outside the city, $10 \mathrm{~km}$ away from a town called Urla. The campus has 3500 hectare of open and $88000 \mathrm{~m} 2$ of constructed areas. The campus was designed with the concept of an isolated enclave related to the vision that academic life would require isolation and concentration and with the expectation that the area would be developed. The latter has not yet happened. Located next to Gulbahce Village, the campus is at the gateway to Karaburun peninsula, and is connected to İzmir by Izmir-Çesme highway. Gülbahce village and the IZTECH campus are not integrated, and most of the students use the shops and the coffee shops that are located in between the two settlements. It is fair to state that the village has neither attracted the faculty members nor the students. There are three major faculties, faculty of architecture, faculty of engineering and faculty of science, and five interdisciplinary programs in the university. There is a student population of 2088 in the undergraduate programs (Table 1) and 674 in the graduate programs, and an academics population of 506 in the campus. As the university has been developed separately both from İzmir city center and Urla, the campus has 50 houses for the academics and 688 dormitory units for the students (Figure 1). There is also a techno-city in the campus established in order to link university education, training and research with industrial production. IZTECH defines its vision as use, development and production of advanced technology and its educational mission as research in co-operation with the industry. As described explicitly in the strategic plan for the 2008-2012 period, the university administration also aims to develop collective life in the campus by supporting communication between different fields. Having production of knowledge and research for the development of technology at the forefront, 
the university strives for exploring an approach toward increase in public benefi ts - both for the community in the university and in the city. For the development of social responsibility, it aims to offer the undergraduate projects contributing to social services for the city. The university also aims to sustain a certain level of satisfaction for both the students and its staff. Its statement underlines the importance of interaction and communication between different members of the university. In that sense, the physical confi guration that defines obvious isolation from the city leaves the collective life confined to the campus.

\begin{tabular}{l|r|l} 
Faculties & Students & Percentage \\
\hline Faculty of Architecture & 443 & 21.21 \\
\hline Faculty of Engineering & 1027 & 49.19 \\
\hline Faculty of Science & 618 & 29.60 \\
\hline Total & 2088 & 100.00
\end{tabular}

Table 1: Population of faculties

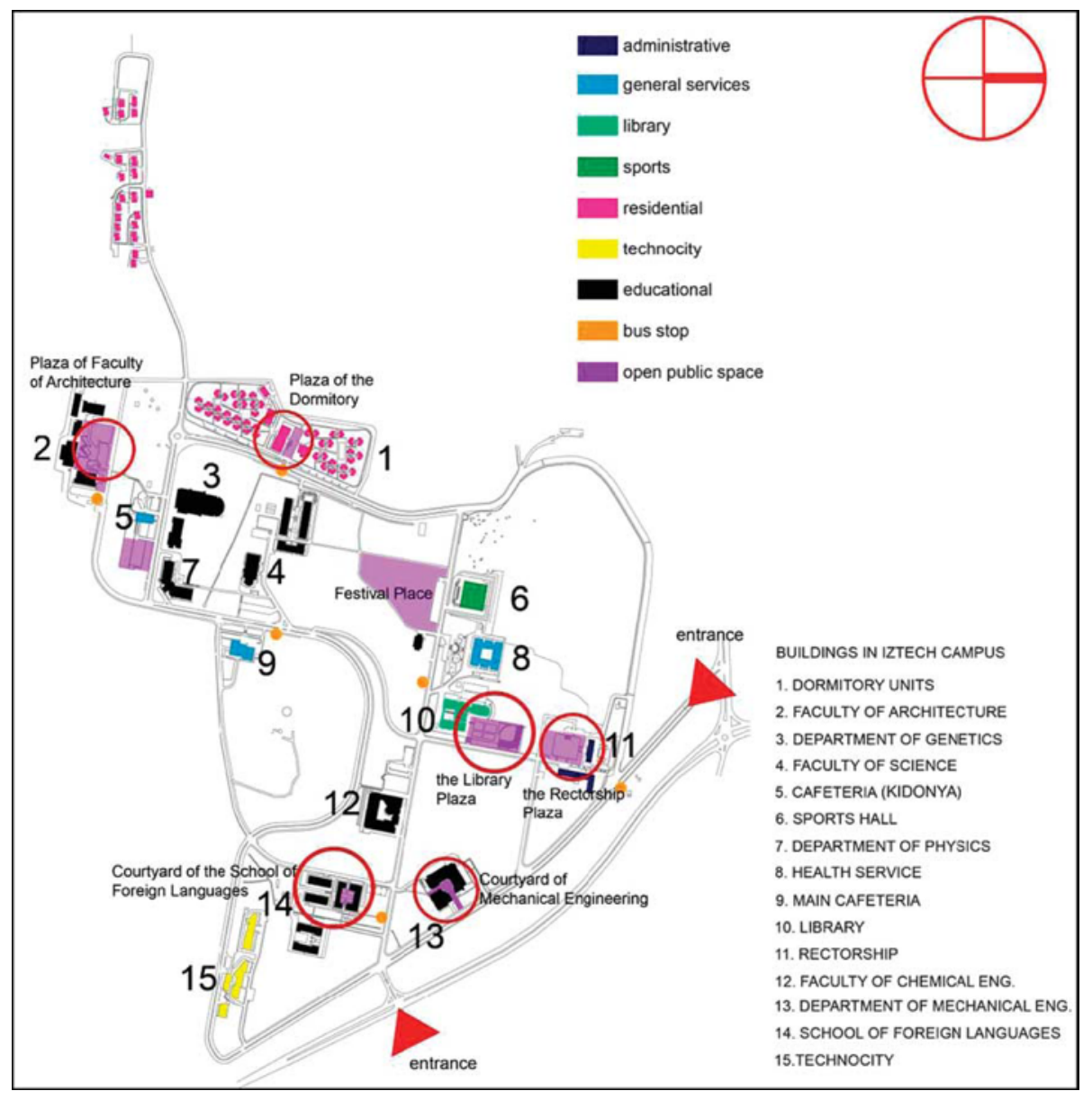

Figure 1: Land use map of IZTECH 
IZTECH campus has easily identifiable physical characteristics. The confi guration of the campus has large shares of open spaces, which separate faculty buildings from each other. There is no23 separate pedestrian walkway that could also have become a promenade; pedestrians use the limited sidewalks parallel to the roads. Dispersed along vast open spaces and connected by roads, and ring, a shuttle service circling the campus every half an hour, buildings require a lot of walking to reach. There is an intentional separation between buildings, where teaching, research and leisure activities are carried out. The distances between separated buildings, level changes in the topography and the lack of shade make walking undesirable. As a consequence, people tend to use cars or the ring service. Our initial observation is that these physical characteristics of campus cause spontaneous social gatherings to occur only locally and close to the buildings.

\section{Research Method}

Physical configuration of IZTECH campus is analyzed using space syntax and visibility graph analyses. The analysis of axial lines according to the method developed within the space syntax theory (Hillier, 1996) is utilized to understand the spatial organization of the campus and the potential spaces for bringing students together. The axial maps are drawn with two types of circulation: pedestrian and car; in this article, the analysis of the pedestrian map is used. Both global (Rn ) and local (R3) level of analysis is applied. Visual graph analysis (VGA) is made by Depthmap, the program created by Turner (2001) and developed at UCL Bartlett. We selected open spaces that were designed as plazas of the campus to be analyzed more in detail. With the use of VGA, this study aims to understand the depth of visual fields in these plazas and examine the locations that give users more visual information or vice versa. VGA analysis has been used to explore the potentials of space for its use and especially for providing stationary activity (Hillier, 1984; Arruda Campos, 1997). These analyses showed that lively open spaces are the ones that are embedded in the urban fabric (both globally and locally integrated), but user preferences for stationary activity in these spaces are inversely related to the increasing degree of the visual connections between public spaces to the surrounding urban environment (Arruda Campos, 1999). In addition, the syntax and the VGA analyses are combined with examining the strategic value. ' Strategic value' determines the potential use of a (open) space in relation to its imbeddedness to the global integration and it is calculated by the sum of the integration values of the axial lines that pass through the space (Arruda Campos, 1997, 1999). Selected plazas are (shown in Figures 1 and 2 with circles): 
1. Plaza of the Faculty of Architecture;

2. The plaza of the dormitory units;

3. The library plaza;

4. The rectorship plaza;

5. Courtyard of the School of Foreign Languages;

6. Open space demarcated by the Department of Mechanical Engineering Building.

In order to explore the socio-spatial activity in campus, students from each department are interviewed using open-ended questionnaire. This was a survey exploring the spatial preference of students with a questionnaire of 11 questions. The questionnaire enabled us to cover an extensive amount of information that could not be acquired from physical characteristics and labeled functions of spaces and would have required year-long sustained observations. Signifi cantly, we aimed to explore open public spaces in order to understand whether they motivate encounter, interaction recreation and engagement with different activities.

In addition, an accompanying visual survey to the questionnaire and VGA analysis was carried out observing students' stationary activity at the same six open spaces. Data related to the stationary activities at these spaces was collected using the snapshot technique. Observations were done on weekdays during April and May 2011 for the lunch time period between 11:45 and 13:00. Stationary activities were recorded every $5 \mathrm{~min}$. Observation time was chosen when the students use the open public spaces for break time. Times of arrival in the morning and departure in the evening are not chosen because the selected open spaces between these times are dominated by the movement of the groups waiting for buses. Static people were grouped into sitting and standing people in the plazas. The snapshot data about stationary activity was overlapped with the VGA graphics (in figures 5 to 10). In these figures, the students in groups are represented with the circles. Finally, integration analysis of the campus and VGA analysis of open public spaces are compared with the results of the questionnaire.

\section{Findings of the Spatial Analysis}

In this section, spatial configuration of the campus through the analysis of axial maps is investigated in order to examine the integration and accessibility between parts of the campus. We found that the global integration value of campus is 0.38 , and the local integration value is 1.64 . Global integration analysis (Rn) (Figure 3) shows that the area containing the most integrated lines follow the main vehicle route connecting one of the two main entrances of the campus to the student housing, which 
includes one of the main cafeterias in the campus, dormitories and shops for students. The most integrated line (0.55) is surrounded by the and sports hall.

The second integrated line (0.53) is connected to themost integrated line and it goes between the student housing and one of the major bus stops. The third most integrated line $(0.52)$ connects the main vehicle route and Faculty of Science Building and is, in fact, a pedestrian path going through the festival area.

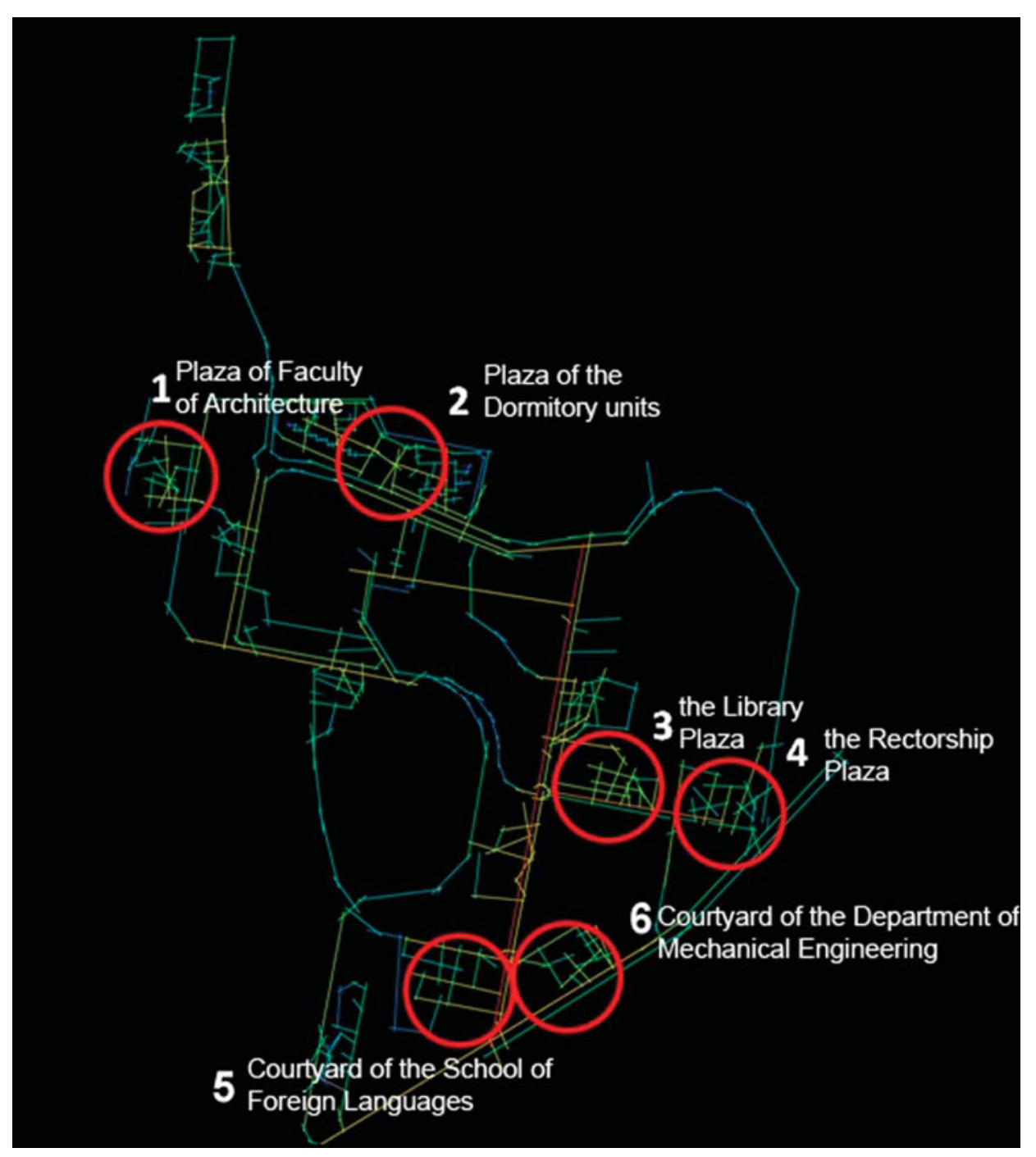

Figure 2: Location of public spaces in the campus. The axial map shows the location of public spaces where the visibility analysis has been performed.service buildings including the library, health service

None of the faculty buildings is located on the most integrated axis except the building of Chemical Engineering faculty. One step away from this axis, there are Mechanical Engineering faculty and Schools of Foreign Language. Rest of the buildings of other science departments, Department of Physics and Molecular Biology and Genetics, are on the axis with average 
integration at the west side of the campus. The clustered buildings of faculty of Architecture are located on one of the segregated axis in the campus. Because the faculty buildings are not directly on the integrated axis and there are no direct paths from the faculty buildings to the integrated axes, access to the main road requires a lot of walking. This calls attention to the segregation of faculty buildings in the campus that are dispersed in the different parts of the campus. As such, the distance between the globally integrated axes and faculty buildings may be the reason why there is relatively less interaction among the students from different departments. Second, although the globally integrated axes between the student housing and the main gate of the campus defi ne a clear route for the pedestrians, they are not used according to their potentials because the axes go through large unoccupied areas, and they are not supported with buildings of education or other public facilities.

Third, the plazas are segregated in the global axial map. The plazas of the library, rectorship and faculty of Architecture have low integrated axes. The plaza of the student housing has three medium integrated axes. On the other hand, the festival area, which has been used for cultural and social organizations in the spring, is located within the globally integrated zone. It is the area where students can meet with the larger population coming from the city during university annual festivals. Although the site does not present welldefined physical boundaries, it is used to have a variety of activities in spring festivals: students can play outdoor sports, listen to public concerts and sometimes camp overnight in this area. Nevertheless, other than that period that lasts 3-5 days in a year, the festival area becomes a derelict site. 

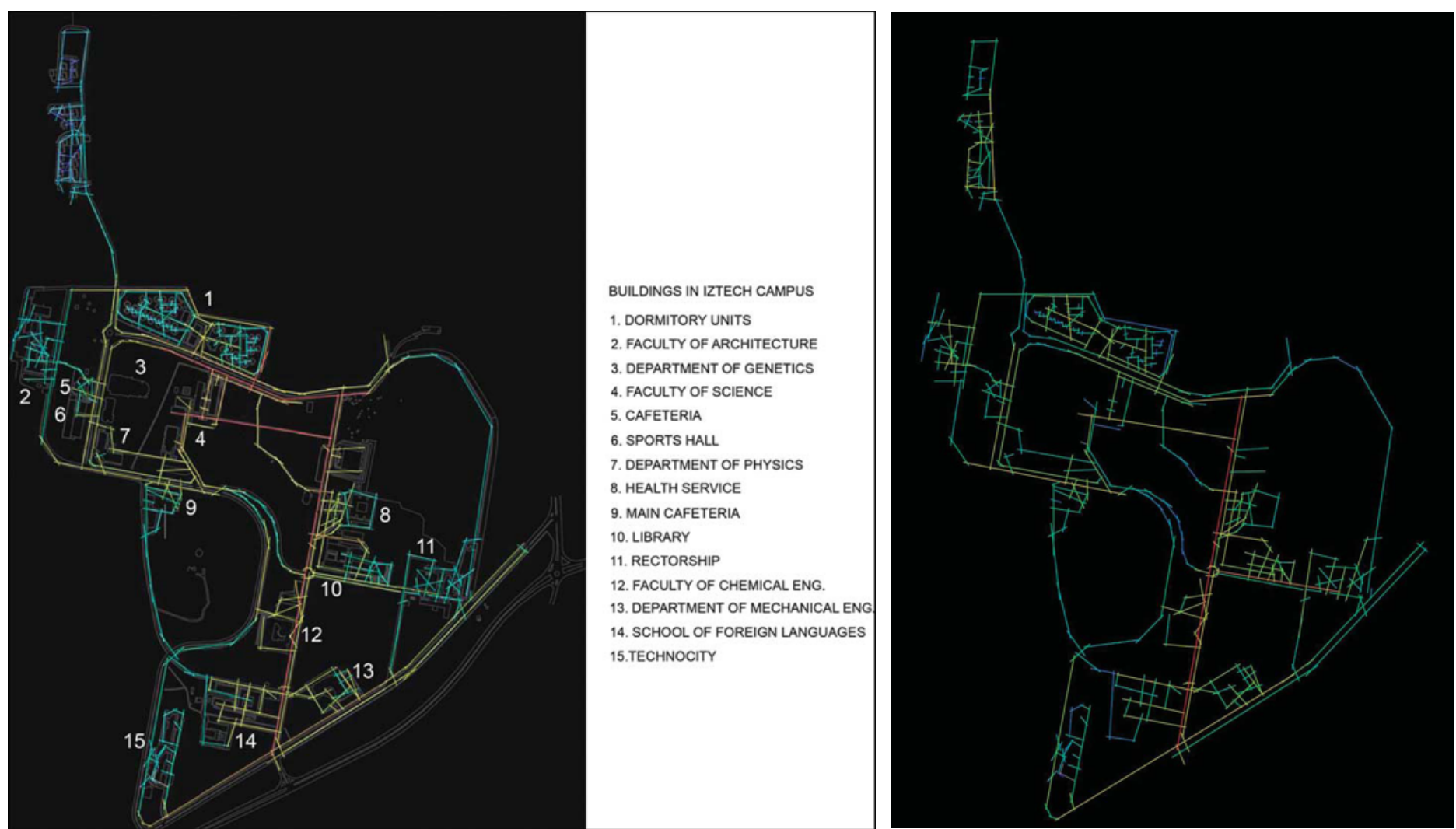

Figure 3 (left): Axial map (global integration). Axial map with map of campus illustrates global integration of campus pedestrian circulation.

Figure 4 (right): Axial map (local integration). Axial map illustrating local integration of campus pedestrian circulation.

As this open space has not been supported with a fine grain of different uses and activities for daily public life of the campus, it becomes underutilized. The local integration pattern (Figure 4) shows that the route between the library and sports hall buildings is the most integrated. The buildings of Chemical Engineering department, library and health services are located on this axis. The buildings of Mechanical Engineering Department and Foreign Language School are located one step away and student housing are located two steps away from this most integrated line. The buildings of faculty of Architecture are not by the locally integrated axes. In terms of local integration, chemical engineering, mechanical engineering and foreign language, school buildings are the most advantageous. They are connected to the most integrated axial lines and they are also two steps away from each other. Relating Visual Integration and Stationary Activity Figures 5 - 10 illustrate the visual integration analysis of the selected plazas juxtaposed with the axial line analysis and the data gathered by observation, which represents the levels of stationary occupancy.

Except the library plaza (Figure 5), in each designed outdoor space, most visually integrated areas are at locations intersecting buildings with the main road. All faculty units are clustered around a common space and these spaces have medium visibility shown in yellow (Figures 7,8 and 9). 
In addition, in each plaza, the visual integration is low at the entrance of the buildings (light blue), where concentration of public activities and gatherings mostly occur. This confirms the findings of Campos that people seem 'to avoid very exposed spaces and prefer areas that provide good views' (Arruda Campos and Golka, 2005) and some level of privacy for unprogrammed static activity (Arruda Campos, 1999). Specifically, in this case, it is possible to interpret that stationary activity occurs in areas close to the spaces that control strategic points, not the whole plaza. Results of snapshot observation present that the plazas of the rectorship and library building (Figures 5 and 6) are preferred less for stationary activities in comparison with the faculty plazas (Figures 7,8 and 9). This may be because of the fact that, although these two plazas are located by globally integrated axis, they are not supported with activities as well as with street furniture. Although these plazas should serve globally, they fail to serve even locally. The responsibility of campus design requires one to realize the axes where potentials of natural movement are higher and can be enhanced with specifi c functions. In this case, rectorship and library plazas seem to be constructed for being platforms of building masses rather than inhabiting users.
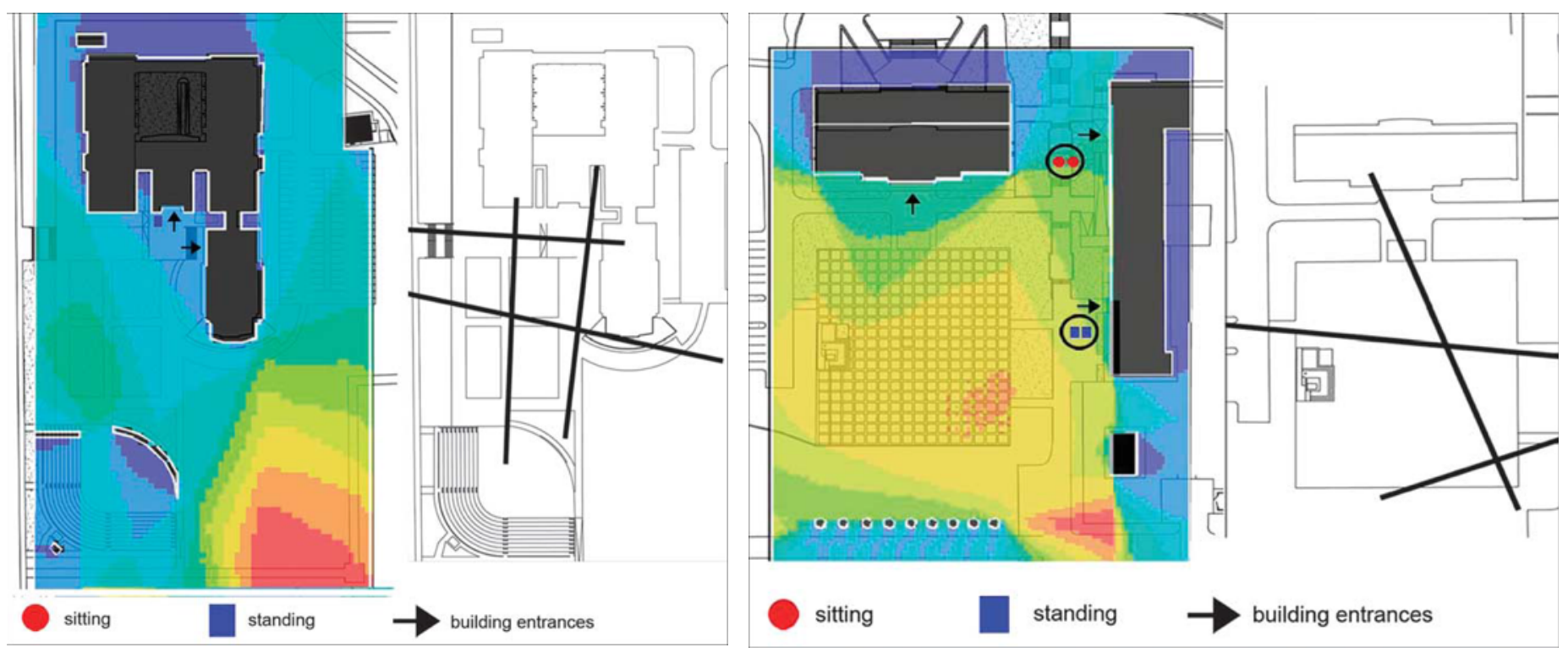

Figure 5 (left): Library plaza. Local axial map and VGA showing the library plaza.

Figure 6 (right) : Rectorship plaza. Local axial map and VGA showing the rectorship plaza. 

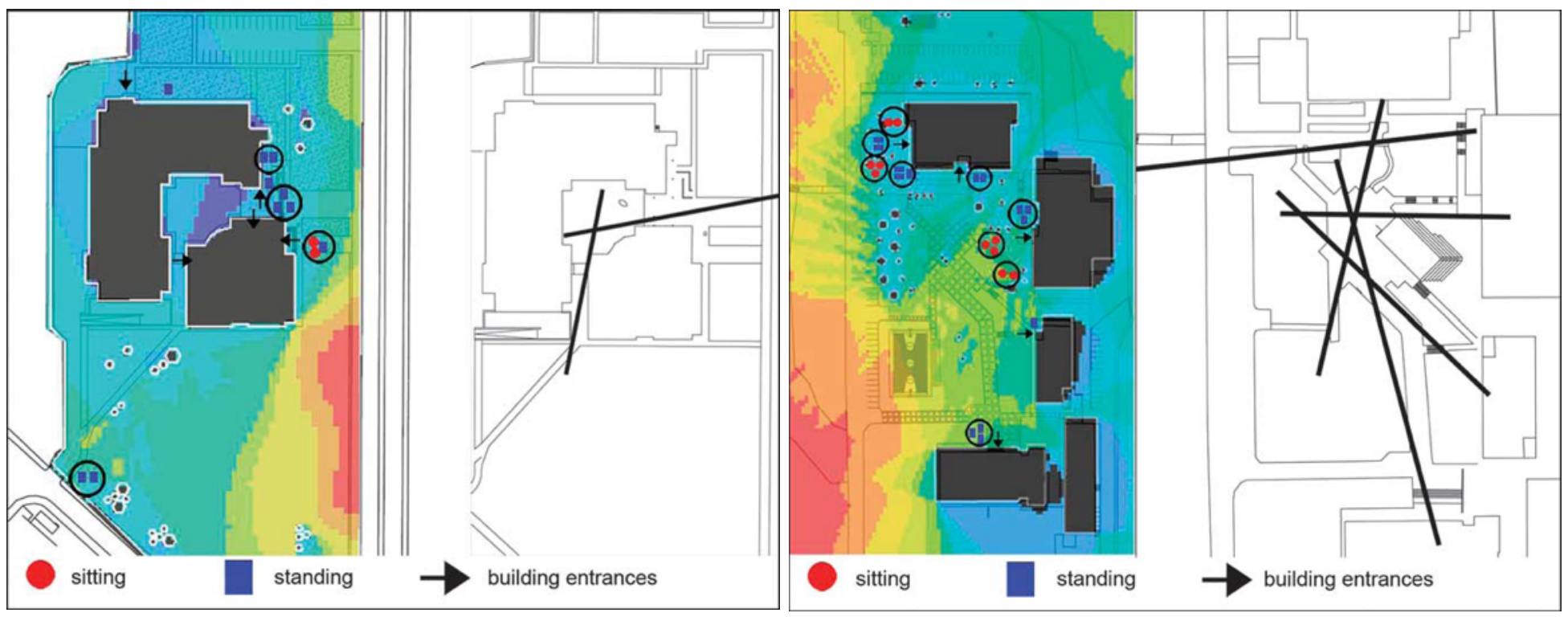

Figure 7 (left): Open spaces of mechanical engineering. Local axial map and VGA showing the open space in front of building of mechanical engineering

Figure 8 (right): Plaza of faculty of architecture. Local axial map and VGA showing the plaza of the dormitory units.
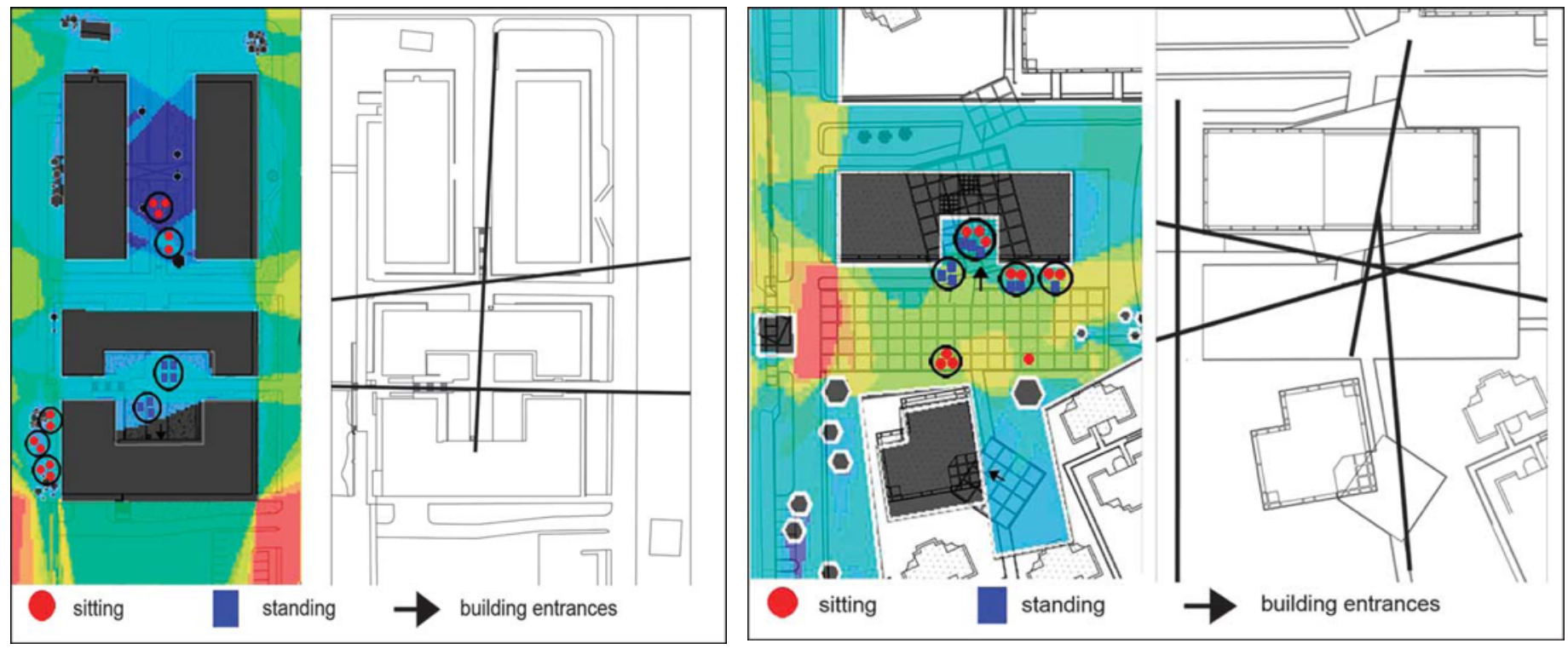

Figure 9 (left): Courtyard of school of foreign languages. Local axial map and VGA showing the plaza of faculty of architecture.

Figure 10 (right): Plaza of dormitory units. Local axial map and VGA showing the courtyard of school of foreign languages. 


\section{Findings of the Questionnaire}

In total, survey questionnaires were applied to 102 undergraduate students who have been selected in proportion to student populations and faculties ( 5 per cent of the students in each faculty population), a high percentage of questionnaires, 97 of them returned; response rate was 95 per cent. With face-to-face interviews, students were randomly selected and questionnaires were distributed at six chosen public spaces in campus during lunch time. Respondents were 45 women (46 per cent) and 52 men (54 per cent). Most of the students (76.3 per cent) were between 18 and 22 years of age. Fiftyfive students (57 per cent) live in the city, whereas 42 students (43 per cent) live in the campus.

The questions in the survey are listed as:

1. Name the open public space that provides the possibility of spontaneous encounter;

2. Name the open public space that provides the possibility of socialization;

3. Name the open public space that provides the possibility of meeting with people outside the campus;

4. Name the open public space that promotes recreation and vitality;

5. Name the open public space that provides the possibility of engagement of different groups of people;

6. Name the open public space that you can use in different times of the day (at nights, at weekends);

7. Name the open public space that you can become aware of the agenda of the university;

8. Name the open public space that you feel free for your actions the most;

9. Name the open public space that makes you feel as an university student the most;

10. Name the open public space that makes you feel safe the most;

11. Name the open public space that you feel relief from the daily problems the most.

Students' total answers to the questionnaire bring two important outcomes about their choice and satisfaction of open public spaces at IZTECH. First, students did not name any specific space for the 45 per cent of the questions or relate any space in the campus to any of the socio-psychological qualities explored in the questions. In a total of 1067 answers of 97 students for 11 questions, there were a total of 481 answers stating 'no place for such kind of activity'. For the Questions 3, 4, 6, 9, 10 and 11, more than the half of the student population gave negative responses stating that 'there is no such place'. Especially for the questions asking the public space that provides the possibility of 
meeting with people outside the campus and the question asking the space that makes you feel as a university student the most, only six specific public

spaces were written. This also informs us about the separation between the students' daily practices from urban life. Answers to the questions related to the psychological experiences of students are surprising: 63 per cent of the respondents have no sense of attachment to any space and or to the university campus. However, apart from these negative responses, we identifi ed three open spaces that are preferred the most (Figure 11). It is interesting to see that along the six open spaces we analyzed only the plaza at the student housing that (Figure 10) was chosen. Others, including the plazas at the globally integrated axes, such as the plaza of the rectorship and the library (Figures 5 and 6), were not selected as preferred places by the students. On the other hand, the two public spaces that we did not include in our VGA analysis and snapshot observations were the other preferred spaces by 20 per cent of the students. These are the festival area (shown in Figure 1) and the canteen of the Faculty of Science Building (shown in Figure 11).1 We have not included these spaces because festival area is not a plaza but an available open area in the campus that is used once a year and is located on the ground fl oor of the Faculty of Science Building; this is not an open space.

1. The plaza of the dormitories (Figure 10): For the students, this was the most preferred space for spontaneous meetings with others from different groups (30 per cent). In addition, it was selected as the space that makes them feel safe the most (21 per cent) and named also for the space ' for use in different times of the day' (19 per cent) and 'provides the possibility of socialization' (17 per cent) and 'awareness about agenda of the university (17 per cent).

2. The Festival area : It was selected as the public space that 'promotes recreation and vitality' (21 per cent with choice of 20 students). Also, it 'provides the possibility of engagement of different groups of people' (19 per cent) and it makes students feel free (20 per cent). The festival site provides a potential for adaptations to different uses with the possibility of participating in different groups.

3. The Canteen of the Faculty of Science Building : Although we specifi cally cautioned respondents to write only open spaces for their answers, it was the only closed public space that was stated as having the possibility of meeting with others. The space must be preferred as it is connected to the two highly integrated lines and being in a walking distance to the student housing. Having the highest undergraduate student population, it attracts students of the closer faculties and serves as a local center. 
The festival area and plaza of the dormitories were selected as the most preferred spaces by students for different kinds of public activities and associated experiences in campus. It is interesting to see that both of them were located on two sides of the most globally integrated axes. These two chosen public spaces can be assumed as similar in syntactic properties in the campus. However, festival area and plaza of dormitory display some differences in their spatial and geographical characteristics: Festival area was preferred by the students in surveys, mostly for social practices promoting vitality, recreation and freedom. However, we observed that it has turned to be a derelict site, except 1 week in a year. This shows that, although it is a popular place for student-based organized activity, it is far from the students' daily routines in campus. This could be related to its geographical conditions and architectural characteristics: it is located on an integrated route and at the crossroads; yet, it is not near to the faculties where students spend most of their time. Students within the dense academic program could not find time to use the area at rush hours between courses. In addition, the absence of defined architectural elements such as sitting places, surface treatments and physical elements to shelter from different weather conditions can be seen as another reason for low usage of space in daily practices. As a consequence, this area promises in the mind of students an idealized zone for entertainment and programmed activities, without being used in its potential. Contrary to the festival area that is defined by nature and green, dormitory units are surrounded with fences and the entrance to the dormitory district is controlled with a gate. This may explain why the students chose the area as safe in different times of the day in a self-contained campus. 


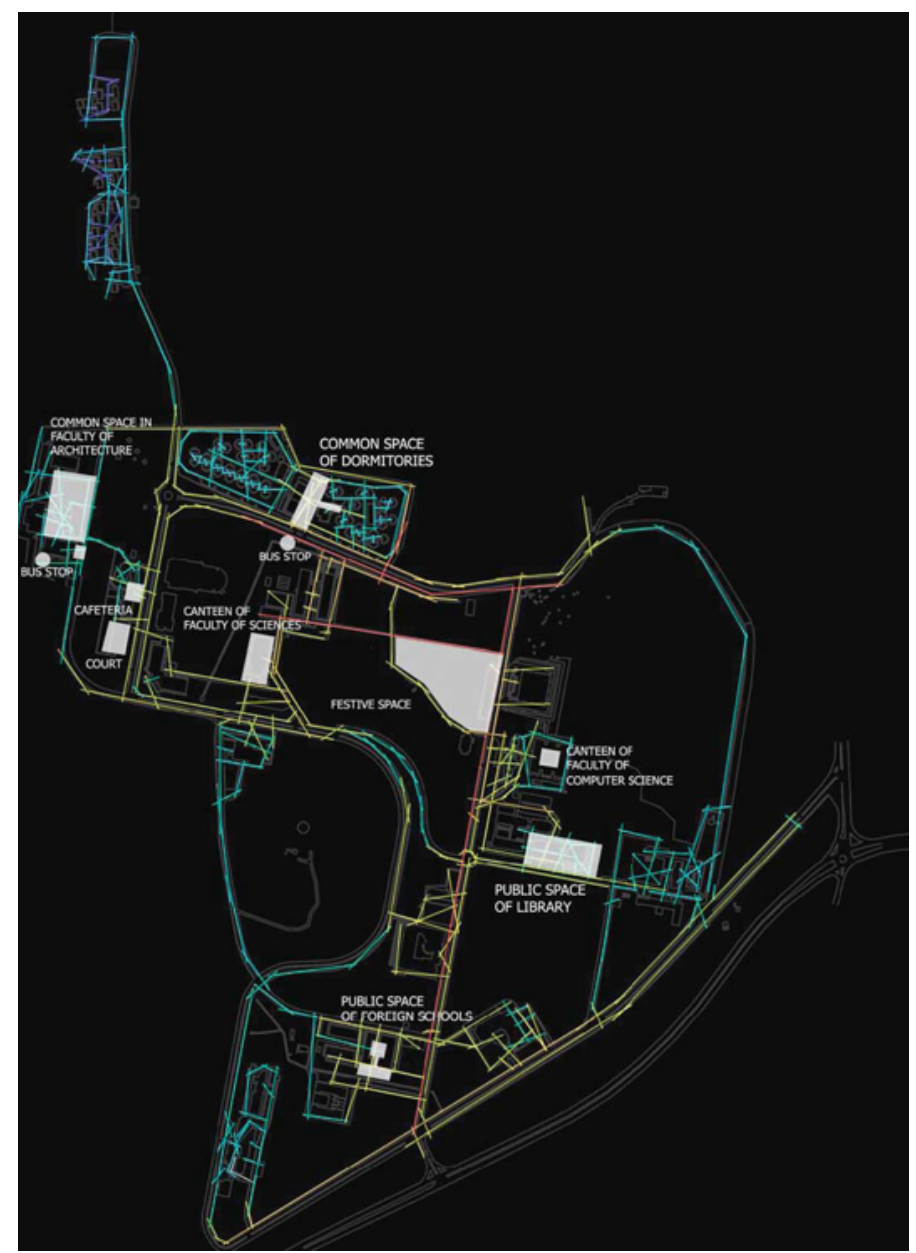

Figure 11: Preferred open spaces. Presentation of results of preferred spaces in questionnaires in the axial map of IZTECH.

\section{Spatial Organization of Campus and the Practices of Students on Public Spaces}

In order to understand the relationship between spatial character or public space and movement patterns of students, we analyzed 'strategic values' of public spaces as defined by Hillier (1996) and later by Arruda Campos (1997). When considering strategic value of each public space (Table 3), we see that the maximum integration value for the plaza at the student housing is 1.82 and for the plaza of Faculty of Architecture is 1.79. Although the strategic value of these two plazas is close, the number of stationary people using these spaces is highly different. In addition, as the festival area has no axial line penetrating the space, it does not have a strategic value.

The analysis showing the relation between the sum of integration values of six public spaces and the stationary occupancy showed insignifi cant correlation. On the other hand, there is a signifi cant correlation between the sum of integration values and the results of questionnaires (Table 3) with $R^{2}=0.71$ for $P=0.035, P \leqslant 0.05$. This is related to the difference in data. Whereas observations show the momentary use of public spaces, results of questionnaires show the choices of students for 
a longer period. In other words, students' answers represent their choices in terms of their year-long practices in the campus. Although the spaces have potentials for collective practices, they are not activated with permanent functions. Even if there are no supporting functions in the plazas, there should be places to sit and relax and well-designed routes for plazas can add to the performance of public space (Arruda Campos, 1997, p. 10). In terms of examining how the axial lines in public space affect the stationary occupancy of students, the number of axial lines penetrating into public space becomes an important determinant of static use of space (Arruda Campos, 1995, 1997). The public spaces, where the highest number of static occupancy was recorded, plazas of student housing and Faculty of Architecture, are those that have the highest number of axial lines (Table 2). On the other hand, as festival area has no axial lines, it was the place where the least number of static occupancy was observed. The analysis shows that the plaza of student housing is a social space that shows a direct correlation between the integration value of axial lines and static occupancy of students. One reason is that it is like home where students from different faculties gather in this 'gated place' and socialize. Also, far from academic life, it promises an informal public life that nurtures free dialog and participation in different times, as identified in surveys.

\begin{tabular}{|l|c|c|c|c|c|c|c|}
\hline \multicolumn{1}{|c|}{ Plazas of } & $\begin{array}{c}\text { Number of } \\
\text { stationary } \\
\text { people }\end{array}$ & $\begin{array}{l}\text { Mean value } \\
\text { of number of } \\
\text { people }\end{array}$ & $\begin{array}{c}\text { Sum Rn } \\
\text { (pedestrian } \\
\text { integration } \\
\text { value) }\end{array}$ & $\begin{array}{c}\text { Sum R3 } \\
\text { (integration } \\
\text { value) }\end{array}$ & $\begin{array}{c}\text { Number } \\
\text { of axial } \\
\text { lines }\end{array}$ & $\begin{array}{c}\text { Number of } \\
\text { selection of } \\
\text { questionnaire }\end{array}$ & $\begin{array}{c}\text { Number of } \\
\text { different } \\
\text { activities } \\
\text { mentioned (11) }\end{array}$ \\
\hline Architecture & 86 & 14.3 & 1.79 & 9.57 & 5 & $47 / 586$ \\
\hline Mechanical Engineering & 39 & 8.7 & 0.64 & 3.47 & 2 & $2 / 586$ \\
\hline Foreign Languages & 113 & 18.8 & 0.97 & 5.58 & 3 & $21 / 586$ & 2 \\
\hline Rectorship & 41 & 6.8 & 1.03 & 5.42 & 3 & $2 / 586$ \\
\hline Library & 87 & 14.5 & 1.63 & 7.8 & 4 & $21 / 586$ \\
\hline Dormitories & 235 & 39.1 & 1.82 & 7.12 & 5 & $130 / 586$ \\
\hline Festival Area & 34 & 5.6 & - & - & - & $80 / 586$ \\
\hline
\end{tabular}




\section{Conclusion}

This research presents an examination of the spatial configuration of IZTECH campus in infl uencing, producing and sustaining public life for its students. Examining open spaces that have the potential to juxtapose global and local axes and foster a lively public life, we analyzed the different socio-psychological public practices of students in these spaces. The global and local integration patterns and visibility analysis of selected open spaces show the potential areas for production of collective life; however, the actual practices of students in the campus are not parallel to the potentials of the spatial configuration. More than half of the respondents either left the answers empty or stated that there is not a place that fi ts as an answer to the question asked in the questionnaire. This shows that the campus is experiencing segregation. In other words, the design of the campus is not utilizing the potential of the integrating movement axes with activities and architectural elements.

Although the low density in the student population can also be assumed as the reason of the low density in use, the morphological character of the campus better explains the reasons in the patterns of use. Owing to the large green areas separating the buildings from each other and the lack of alternative pedestrian routes, buildings required long walks to reach. The observation of public life in the campus shows that students prefer staying inside the buildings where they can study, eat and socialize but cannot experience public life outside. For example, they prefer the canteens of faculty buildings for the gatherings rather than the plazas designed for such use, although the weather conditions permit such outdoor gatherings. Although plazas are located in integrated zones, their boundary conditions, lack of furniture and activity supporting stationary use disable them to become public platforms. In addition, festival area, which was not designed as a plaza, is at the syntactic center of the campus and can be transformed into a public space for everyday use with additional functions and furniture supporting long stays. The relationship of the faculty buildings with the public spaces is not well integrated either. They are rather attached to the open areas in front of them haphazardly. As these open areas do not present comfortable and enjoyable zones, collective life in front of the buildings are mostly formed according to short and necessary activities of students such as eating a sandwich and waiting for transportations. Faculty buildings are segregated globally from each other. In other words, educational buildings turn to be specialized and isolated objects in the vast open areas in the campus. This provides isolation and privacy for learning and teaching environment while promoting the collective life through only a local scale. However, thinking process of learning and teaching as a social activity provides an improved understanding of social underpinnings of collective life in the university campus. In this respect, public spaces for 
this learning environment have crucial roles and they should not be conceived as leftover spaces between faculties. Providing welcoming collective around the faculties and confi guring buildings with a good balance in a different use along the integrated axes are part of the development of collective life in the campuses. The focus should be on networks providing interaction between faculty buildings and open spaces together. This will provide a vivid and stimulating public life in the campus that they will contribute to the production of the public realm in general.

\section{Note}

${ }^{1}$ In order to identify most preferred public spaces, we regarded spaces that were selected at least by 20 per cent of the student population and more.

\section{References}

Adhya, A. (2009) In: D. Koch, L. Marcus and J. Steen (eds.) Evaluating the Campus-Downtown the Spatial Configuration of Four College Towns. Proceedings of Seventh International Space Syntax Symposium; 8-11 June, Stockholm: KTH.

Arruda Campos, M.B. (1995) A Morphological Analysis of Urban Squares in European Towns. Bartlett School of Graduate Studies, University College London. Unpublished.

Arruda Campos, M.B. (1997) Strategic Spaces: Patterns of Use in Public Squares in the City of London. Proceedings of 1st Space Syntax Symposium; April, London.

Arruda Campos, M.B. (1999) All That Meets the Ey: Overlapping Isovists as a Tool for Understanding Preferable Location of Static People in Public Squares. Proceedings of 2nd Space Syntax Symposium; March, Brasilia.

Arruda Campos, M.B. and Golka, T. (2005) Public Spaces Revisited: A Study of the Relationship between Patterns of Stationary Activity and Visual Fields. Proceedings of 5th Space Syntax Symposium; 13-17 June, Delft.

Barros, A.P., Silva, P.C., Holanda, F., Medeiros, V. and Fortes, J.A (2009) In: D. Koch, L. Marcus and J. Steen (eds.) Transport Mobility at the University of Brasilia, Brazil. Proceedings of Seventh International Space Syntax Symposium; 8-11 June, Stockholm: KTH.

Bowman, A. (2011) Beyond the 1vory tower: In search of a new form for campus-community relationship. MSc thesis, MIT, Massachusetts.

Brockliss, L. (2000) Gown and town: The university and city in Europe, 1200-2000. Minerva 38(2): 147-170.

Calhoun, C. (2006) The University and the public good. Thesis Eleven 84(7): 7-46.

Chapman, M.P. (1999) The campus at the millennium: A plea for community and place. Planning for Higher Education 27(4): 25-31.

Chapman, M.P. (2006) American Places: In Search of the Twenty-First Century Campus. Westport, CT: Praeger Publishers.

Chatterton, P. (1999) University students and city centres: The formation of exclusive geographies, the case of Bristol. Geoforum 30: 117-133.

Christ, C. (2005) Living in public. Places 17(1): 22-25.

Christiaanse, K. (2004) Campus to City: Urban Design for Universities.

Davis, M. and Davis, T. (1990) An urban design proposal for the university of Miami campus master plan competition. Journal of Architectural Education 43(4): 8-15.

Delanty, G. (1998) The idea of the university in the global era. Social Epistomology 12(1): 3-21.

Delanty, G. (2001a) Challenging Knowledge. Philadelphia, PA: Open University Press.

Delanty, G. (2001b) The university in knowledge society. Organization 8(2): 149-153.

Delanty, G. (2008) Rethinking the University: The Autonomy, Contestation and Reflexivity of Knowledge. Social Epistemology 37-41. 
Greene, M. and Penn, A. (1997) Socio-Spatial Analysis of Four University Campuses: The Implications of Spatial Configuration on Creation and Transmission of Knowledge. Proceedings of the 1st international Space Syntax Symposium; April, London.

Gumprecht, B. (2003) The American college town. The Geographical Review 93(1): 51-80.

Halsband, F. (2005) Campuses in place. Places 17(1): 4-11.

Hashimshony, R. and Haina, J. (2006) Designing the university of the future. Planning for Higher Education 34(2): 5-19.

Hillier, B. (1984) Mansion House Square Inquiry - Proof of Evidence, Unit for Architectural Studies.

Hillier, B. (1996) Space is the Machine. Cambridge, UK: Cambridge University Press.

Hillier, B. and Hanson, J. (1984) The Social Logic of Space. Cambridge, UK: Cambridge University Press.

Kim, Y. (2009) In: D. Koch, L. Marcus and J. Steen (eds.) Difference of Place Vitality in Two Central Plazas. Proceedings of Seventh International Space Syntax Symposium; 8-11 June, Stockholm: KTH.

Kumar, K. (1997) The need for place. In: A. Smith and F. Webster (eds.) The Postmodern University? Contested Visions of Higher Education in Society. Bristol, UK: SRHE and Open University Press, pp. 27-36.

Muthesius, S. (2000) The Postwar University: Utopianist Campus and College. New Haven, CT: Yale University Press.

Neuman, D. (2003) Campus planning. In: D. Neuman (ed.) Building Type Basics for College and University Facilities. New Jersey: John Wiley \& Sons, pp. 1-43.

Pusser, B. (2006) Reconsidering higher education and the public good. In: W.G. Tierney (ed.) Governance and the Public Good. Albany, NY: New York Press, pp. 11-27.

Readings, B. (1996) The University in Ruins. Cambridge, MA: Harvard University Press.

Schwander, C., Kohlert, C. and Aras, R. (2012) CAMPUSANALYST: Towards a Spatial Benchmarking System for University Campuses. Proceedings of 8th International Space Syntax Symposium; 3-6 January, Santiago.

Srouri, D. (ed.) (2005) Colleges of Cambridge: The Spatial Interaction between the Town and the Gown. Proceedings of Fifth International Space Syntax Symposium; 13-17 June, Delft. Delft: Space Syntax Laboratory.

Temple, P. (2008) Learning spaces in higher education: An under-researched topic. London Review of Education 6(3): 229-241.

Trigueiro, E. and Onofre, C. (2009) In: D. Koch, L. Marcus and J. Steen (eds.) Finding Ways around the Campus: A Study to Support a New Signage System for a University Campus in Natal, Brazil. Proceedings of Seventh International Space Syntax Symposium; 8-11 June, Stockholm: KTH.

Turner, P.V. (1987) Campus: An American Planning Tradition. New York: Architectural History Foundation.

Turner, A. (2001) Depthmap: A Program to Perform Visibility Graph Analysis. Proceedings of the 3rd International Space Syntax Symposium, Atlanta: Georgia Institute of Technology.

Whisnant, D. (1979) The university as a space and the future of the university. The Journal of Higher Education 50(4): 544-558.

Yanni, C. (2006) Why all campuses need public places. The Chronicle of Higher Education 52(B21). 